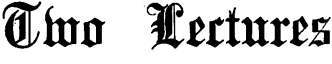

ON

\section{SOME THOUGHTS ON THE PRINCIPLES OF LOCAL TREATMENT IN DISEASES OF THE UPPER AIR PASSAGES.}

Delivered at the Medical Graduates' College and Polyclinic on October 2nd and 9th, 1901,

By Sir FELIX SEMON, M.D., F.R.C.P.

LECTURE I.

Gentlemen,-In the remarkable address on "Friends in Council" recently delivered before the British Medical Association at Cheltenham, and in which both the profession and the public got to hear a number of excellent, though perhaps not exactly palatable, home truths, Dr. Goodhart in speaking of "patients" makes the following statement: "With what impatience do men and women in the present day rush into the not always sufficiently repellent arms of surgery. A little pain unnerves them, and all they know of surgery is its successful side. It is a day of great things, and why should they not have the benefit of these advances? And so with an ache here or a pain there they undergo an operation." And further on he says of "doctors": "I do not doubt, I say, that everyone of us does his best for the man that consults him, but $I$ am not sure that in attending to the exigencies of the immediate present we do sufficiently take heed of the future. And our failings in this respect are closely bound up with those of our patients, for we in our place are so anxious to overlook nothing and to cure disease, so enthusiastic in our belief in our power to accomplish what we wish. First may be put a morbid readiness on our part to detect disease. Engaged as we are in this pursuit, there comes a risk that we too little appreciate the wide range of health, that is, how good a state of health is compatible with numberless slight and even sometimes considerable departures from normal We tend to make our standard too severe for practical purposes."

It did not require Dr. Goodhart's further specific charge, namely, that " throats and noses suffered terribly from this lust of operation that has beset the public," to convince me that I could not do better than to introduce what I have long intended to say on the question of the principles of local treatment in diseases of the upper air passages, than by quoting the above wise words, for they tersely and accurately describe, in my opinion, the present state of the question. Not that I wish to bring a special charge against my own special branch. Dr. Goodhart's fearless denunciation shows that the "lust of operation" is, indeed, a general characteristic of the present phase of medical development. But coming from the general to the particular, and speaking of such matters only of which I can claim personal cognisance, I am afraid I must fully endorse his statement so far as diseases of the upper air passages are concerned. Not only is local or operative treatment of these parts resorted to in numberless cases, where, to say the least, it is not required; not only do operations of inestimable value in really suitable cases become discredited through being performed wholesale; not only is the old war-cry against specialism, namely, that it engendered narrow-mindedness, heard again, and this time, I am afraid with greater justification than on previous occasions; but, worst of all, laryngology and rhinology as a whole are being held responsible for the overzeal of one advanced section.

Under these circumstances no apology is needed for a serious protest coming from within against the "lust of operation," and for an attempt to propose some simple principles which might advantageously guide our local activity in diseases of the upper air passages. This is the purpose of my lectures. Before 1 have gone far, you will have seen, I trust, that declaring against exaggerations does not in the least mean counselling procrastination or giving pusillanimous advice in cases in which prompt and energetic local interference is actually required.

Let me begin, then, by recording my own conviction that it is in the nature of things, when a part of the human body has been made more accessible to eye and hand by the progress of our science, that the treatment of affections of that part should gradually change frcm the medical to the surgical, or, at any rate, from the general to the topical side. The rationale of this change is obvious. Instead of pouring, as it has been satirically described, "diugs of which we know little into a body of which we know less," with the sometimes rather vague hope that some of the constituents of our mixture may reach and favourably influence the affection from which our patient suffers, we, by the substitution of local for general treatment, either modify by topical applications, the effect of which can be accurately watched, the course of the disease, or, in another number of cases, remove it altogether by surgical interference. That such a change, broadly speaking, is almost always of the nature of a distinct therapeutical advance-although, as will be hereafter shown, important exceptions exist to that rule -is conclusively proved by the increase of our healing power during the last fifty years.

The triumphs of cerebral and abdominal surgery admit of no dispute, and, were further proof needed, it is given by the great progress we have made in the treatment of diseases of the upper air passages. Where forty years ago the practitioner treated the symptom "hoarseness" by drugs and climatic changes, often enough in complete ignorance whether that symptom depended upon a simple catarrhal inflammation, upon syphilis, tuberculosis, an innocent growth, malignant disease, or paralysis of the larynx, we are now enabled not merely to accurately differentiate between these contingencies, but also to actually cure by topical applications or operation, if not all, yet certainly the majority, of the diseases named. Where thirty years ago the child who could not breathe through the nose and kept its mouth open was censured by parents and governesses for this "bad habit," and was allowed to grow up with retracted chest, deformed face, crippled in its general development, and living under a constant cloud of ear complications, we now, by the removal of adenoid vegetations, obtain -in really suitable cases, be it said-an equally surprising and pleasing change for the better in all these respects. Where twenty years ago patients suffering from what was at that time called "chronic nasal catarrh," accompanied by frequent frontal headaches and by symptoms referable to the absorption of the poisonous discharge which they constantly swallowed during the night into the digestive organs; were treated with sedatives, stomachics, changes of air; and equally harmless and useless snuffs, we now discover in many such cases the cause of all the trouble in an empyema of one or another of the nasal accessory cavities, and by surgical treatment relieve the patient lastingly.

These illustrations could be easily multiplied, but they will suffice, I think, to show the great and manifold progress made through the introduction of local treatment in a number of equally frequent and troublesome affections of the upper air passages.

Whilst this must be unreservedly, and, indeed, most gratefully, acknowledged, it is a very different question whether the length to which the substitution of local for general treatment has gone has been an unmixed blessing. Unfortunately in almost every sphere of human activity the most useful and desirable innovations are apt to be exaggerated, and, indeed, it would almost seem that this danger is the greater in proportion to the intrinsic value of the original movement. Whilst illustrations of this may be seen almost daily in art, in commerce, in industry, and in science a study of the development of modern medicine in particular, will show that, in spite of many disappointing experiences, almost every pragress in our art is apt to become at first disproportionately exaggerated, later on equally disproportionately deprecated, and finally to emerge often enough, if at all, with considerable diminution of its original prestige.

Need I mention the indiscriminate recommendation of many excellent remedies, which, though effectual enough in certain definite diseases, were at one time advocated for every disease under the sun; the boundless, but so soon blighted, [2I 3 I ] 
hopes after the introduction of tuberculin; the excessive employment in bygone days of electricity as a therapeutical agent; and particularly the hyperactivity which we see so often follow the introduction of new and in themselves excellent operations?

What has always appeared to me most remarkable when reviewing these experiences is that the lessons they teach should be taken so little to heart. Time after time one sees that, nothing daunted by the most recent and unpleasant experiences of a similar kind, exaggerations of a truly astounding nature are again indulged in as soon as a hopeful medical progress is made, and again and over again one witnesses the completion of the cycle of overestimation, underrating, and return to soberness.

The method of local treatment of diseases of the upper air passages has, I am sorry to say, not formed an exception to the course of events just sketched. More than once it has had to pay the penalty of its success, and it still pays it periodically, whenever a promising innovation is being made. There is no better illustration of this than the whole history of modern rhinology. Comparing our present knowledge of diseases of the nose with what it was twenty years ago, there cannot be the least doubt, that much important progress has been made. But no sooner was a hopeful rhinological innovation introduced than it was most grossly exaggerated, and no sooner had the exaggeration been recognised and minds had begun to cool down, than the place of the old idol was taken by a new fetish, which in turn was worshipped with equal enthusiasm.

It suffices to remind you of necrosing ethmoiditis, of the nasal reflex neuroses, of the deflections and spurs of the nasal septum, of the hypertrophies of the posterior ends of the lower turbinated bodies, of the latest fad : the "physiological insufficiency" of nasal breathing, and of all the exaggerated hopes and unnecessary operations in turn connected with theseconditions, which during the last twenty years have relieved one another like sentinels on guard, to prove that my description is anything but fantastic. Whether it be increased facility of diagnosis; be it the undeniable triumphs obtained in many affections of the nose and throat, which formerly ranked amongst the incurable; be it an evergrowing conviction on the part both of the profession and the public, that all affections of these parts ought to be locally treated; be it the modern teaching that a large number of the most obscure diseases of the human race, even if situated in remote parts of the body, are in reality due to affections of the npper air passages; be it, as it probably is, a combination of all these factors, there can hardly be any doubt, I think, that local, and more particularly operative, treatment of these parts, excellent as it is in really suitable cases; has of late years been considerably overdone, and that there is a marked tendency to further overdo it.

In this connection it is interesting to inquire who have been the greater sinners, the profession or the public? Dr. Goodhart seems to think that the greater share of the blame falls upon the public. He argues, if I understand him correctly, that the modern patient forces his doctor's hands by demanding a certain article from him, and that the latter only errs by yielding to that demand. Undoubtedly there is a good deal of truth in that,argument, and nowhere perhaps is this more evident than in the subject now under consideration. The public themselves have become so keenly alive to the great progress made, thanks to the introduction of local treatment, in the therapeutics of so many of the affections of the npper air passages, that they have rushed to the conclusion, though very faulty, yet perfectly feasible and pardonable, that all diseases of these parts are amenable to local treatment and ought to be treated locally. They therefore consult the doctor, and particularly the specialist, with the set notion that either some local application will be prescribed for them. or that some operation will be performed. How often do I see undisguised disappointment on a face when I have explained to : its owner that his case was one for general, not for topical treatment; how often do I hear, when I think I have succeeded in making it quite clear to a patient that his local sensations depended upon disturbances of his general health, which in reality required being attended to, $46 . \mathrm{But}$ won't you give me a gargle ? $^{\prime \prime}$ it very much depends upon the doctor's strength of mind, whether, he will under such circum- stances insist upon the line which he himself considers to be the right one, or whether he will flatter the patient's whims by giving him an innocent local placebo in addition to the constitutional treatment which is obviously indicated. There is undoubtedly something to be said in favour of the latter alternative. As Dr. Goodhart truly remarks: "There are times when the sick are not reasonable beings, and unless they have a bottle of medicine"-or shall we in our special case say a gargle, or a paint, or an inhalation?-"to anchor their faith to (oh, shifting sands!) they are in a state of unrest that is positively harmful to their progress." That is certainly true. And, further, when with a little knowledge of the world, and with plenty of previous experiences to guide one, one sees that the patient, disappointed at not getting what he wants, thinks: "That doctor does not understand my complaint," and that he is sure to fall into the hands of the topical enthusiast, or of somebody worse, who will be equally sure to mulct him in a perfectly unnecessary operation, one is confronted by the difficult question whether in the patient's own interest it would not have been better to comply with his wish and to give him something local which, if absolutely useless, would have been at any rate equally harmless, and would have set his mind at rest. I dare not say that this "pia fraus" must never be practised. But against it are three very grave reasons, which I would particularly recommend to your consideration. In the first place, when prescribing some local application, which, of course, has to be repeated at stated intervals, you involuntarily become the patient's accomplice by concentrating his mind on his local sensations. whilst in his own interest you ought by all possible means to divert it from them. Secondly, you lend yourself to supporting the general notion, which you know is neither correct nor-desirable, namely, that all affections of the upper air passages ought to be treated locally. And, thirdly, and most serious of all, by yielding to the temptation you may unconsciously, and with the best intentions of the world, yet very actually, transgress the line between legitimate practice and quackery. Under all circumstances, therefore, the pious deception of which I have just spoken ought to be practised only in the rarest of cases, and the doctor ought to stiffen his back and harden his heart against meekly complying with every unreasonable wish expressed by an unreasonable patient. Better, I think, to lose such a one if he will not listen to well-meant advice than to have to confess to yourself that you have descended to the level of habitually acting against your own better conviction.

But, gentlemen, can we really lay the flattering unction to our souls that in this whole matter the public is the sole tempter, and that our profession merely sins passively by yielding to the temptation? I must confess $I$ do not think that question can honestly be answered in the affirmative. In my opinion and experience the "lust of operation" (including in the word "operation" other forms of local treatment as well) besets not only the public, but also a considerable number of doctors; and I think it cannot be seriously questioned that in the great majority of cases the initial suggestion of operative or local interference comes, not from the patient, but from the medical adviser himself. It will, of course, be said : that is as it ought to be, and I certainly am the last person to dispute that the initiative of any treatment should be taken by the doctor, instead of his hands being forced by the patient. What I maintain is that the frequency with which. local interference is advised and practised nowadays is unfortunately far in excess of actual requirements; that operations are performed wholesele where they are not needed, that operative proposals are being made and carried out on an extensive scale on the basis of some unproven theory, and that. the operative interference itself, often enough, is unduly severe and protracted in proportion to the smallness of the complaint for which it is undertaken. It will be my duty further on, when we come to details, to substantiate these serious assertions, and I feel confident that I shall be able to do so, but I have again to touch upon that sore question, which formed the starting point of my observations, in the present connection, because 1 do not think it fair to lay the whole blame of the modern "lust of operation" upon the public alone, and because I honestly beliêve that the operative Hotspurs amongst ourselves deserve at least an equal share of reprobation. 
This, I trust, is neither a rash nor an uncharitable statement. Whilst making it I am fully aware that in questions of treatment there is very often legitimate room for considerable differences of opinion; that the more enthusiastic and therapeutically active section of our profession is actuated by motives as honourable as those of the more sceptical section, and that to the former we are indebted for most of the therapeutioal advances of the present day. But when all these reservations have been made and duly considered, there remains no doubt in my mind that there are not a few amongst us who are, as Dr. Goodhart has put it, "so enthusiastic in their belief in their power to accomplish what they wish," that their zeal but too often greatly outruns their discretion. Starting with a "morbid readiness to detect disease," they suspect the cause of all ills to which human flesh is heir to be situated in their own favourite little nook, and, when they detect the smallest deviation from the normal there, they persuade themselves that they hove discovered the true source of the patient's complaint, and immediately proceed to.demolish it with fire and sword.

Indeed, your "radical localist" is a much more formidable and actively mischievous person than the poor country practitioner who caustics his influential patient's throat because the latter insists that "something should be done" for him! Whilst he of the country succumbs occasionallyparce qu'il faut vivre, as the tailor said to Talleyrand-the thorough believer in local disease and local treatment quand même slaughters hecatombs of his own free will! In every patient that enters his consulting room he sees a prey to the arrow of his local treatment, and when he writes or speaks of his experiences, you read or hear with astonishment of the dozens or hundreds of cases in which he has found it necessary to perform certain operations and in which he has obtained "excellent results," whilst moreover you, with a not altogether contemptible practice of your own, can recollect but a few cases in which you have considered the operation in question indicated, and whilst you happen to know.that the subsequent experiences of some of the patients on whom these operations had been performed by their perfervid advocate do not by any means justify his glowing account!

The funniest part of the whole business-if in such serious matters one may speak of fun at all-is, that almost every one of the stalwart fraternity has some pet operation of his own, to which he apparently resorts under all circumstances. I confess to serious misgivings when I see it stated that Dr. X. opened more than 500 maxillary antra within a comparatively few years; that Dr. Y. finds it necessary to employ the nasal saw "almost daily," and that Dr. Z. discovers "varicose veins" at the base of the tongue or in the pharynx in every third or fourth patient, necessitating, it would appear, in his opinion, the application of the galvano-cautery in a goodly proportion of them. Statements of that kind, which are not at all uncommon nowadays, justify, I am afraid, more than sufficiently the ever-growing feeling against local overactivity in this territory of medicine, which he who runs cannot help having observed of late-a feeling, let me assure you, which is shared by no one more strongly than by the large moderate section of laryngologists and rhinologists, who from the nature of their calling, have probably more opportunity of seeing what is going on than the profession at large, and who, I repeat, resent it the more keenly, as their whole speciality is held responsible for the excessive activity of its radical section. They see with sincere regret that a revolt is preparing against particular operations and forms of local treatment, which in suitable cases are most useful, but in which the therapeutic zeal of the localist has been most conspicuous and aggressive of late years. They foresee from analogous experiences that the reaction which is brewing may engulf not only the excesses, against which it is directed, but the method itself, excellent though it be in really suitable cases. I feel sure that before this a protest would have been raised from their midst against what they themselves consider as excessive zeal, had not the same easily intelligible personal considerations, which have for a long time prevented me from speaking out, also, with one exception to which I shall further on specially refer, tied their tongues and pens. At last, however, the time appears to have come, when it would seem almost a duty to criticise fearlessly the present state of matters and to try and bring about a greater con sensus of opinion than prevails nowadays concerning the principles which ought to guide us in the local treatment of affections of the upper oir passages.

That complete unanimity concerning these principles will ever be obtained I do not venture to hope myself. Two eircumstances prevent such a happy consummation.

First of all, as I have just endeavoured to show, the personal element enters so largely into all questions of treatment; both so far as the patient's and as the medical adviser's temperaments are concerned, that no universal formula will ever be found applicable to all cases. So long as there shall be differences in education, in intellect, in character-and these differences will of course continue to the end of the chapterwe shall have to shape our treatment in accordance with the peculiarities of each individual patient, and on what this treatment should be the opinions of medical optimists and pessimists will vary equally persistently.

The second point which tells against the laying down and the adoption of any general principles in the treatment of diseases of the upper air passages is the undeniable fact that our views as to whether local or general treatment should be adopted are so liable to be changed by any new discovery, that what seemed essential and indeed indispensable yesterday, may be completely thrown over to-morrow. In the introductory passages of this lecture it has been stated that whilst nowadays the treatment of these affections usually progresses from the general to the topical, we were occasionally met by a movement in the opposite direction. The best illustration of the truth of this statement is afforded by the modern history of the treatment of diphtheria. Whilst, of course, general measures were never neglected by thoughtful physicians in the therapeutics of that formidable disease, the local treatment of its local phenomena developed more and more as time went on. Caustics and astringents, resolvents and antiseptics, heat and cold, varnishes, papaine, peroxide of hydrogen, and a legion of other local applications were recommended and assiduously used to stop the local process. All of a sudden the serum treatment is introduced, and, behold, equally suddenly an end is made of almost all the local therapeutics. True, cleansing remedies and various inhalations are still used, and intubation or tracheotomy may still be required by way of local treatment, but on the whole there can be no question that local has been victoriously superseded by general treatment in this important disease.

What we have witnessed in diphtheria we are likely to see not infrequently repeated, possibly in the near future, in other affections also, if, as may be fairly hoped, further progress should be made with the antitoxin and serum treatment. Whilst, unfortunately, there can be hardly any doubt that the tuberculin treatment in its original form was prematurely inaugurated and adopted, it appears to me equally certain that Koch's fundamental idea was a most important move in the right direction, and it may justly be hoped, that, with further perfection of the method, we may some day succeed in killing the tubercle bacillus in the living tissues of the body without damaging the latter. When that goal has been achieved, there will in all probability be an end to, or at any rate, very little further necessity for, the surgical treatment of local manifestations of tuberculosis. Hence all the local measures in, say, tuberculosis of the larynx, such as curetting, lactic acid applications, etc., which we at this moment justly look upon as important advances in the treatment of one of the most cruel complications of pulmonary tuberculosis, may one day all of a sudden come to belong to the curiosities of a bygone age! And unless it be considered too utopian, it may even be hoped that the day will dawn, when, what has been obtained in diphtheria and in syphilis, and what may fairly be looked for in tuberculosis, may also be obtained in that most cruel of all human scourges -cancer.

From the foregoing you will have seen, gentlemen, that I am very far from flattering myself that any principles of local treatment of the upper air passages which may be proposed have any chance of becoming universally adopted or of being eternally followed. But when all has been said and freely admitted, enough remains which makes it urgently desirable that in our own day a greater consensus of opinion should be obtained as to what is desirable in the way of local treatment of diseases of the upper air passages, and how it should be 
carried out, than exists at the present moment. The future will have to take care of itself.

In the following it is, of course, not my intention to discuss separately or even indeed to mention every single disease of the upper air passages, to describe every indication for its local treatment, or to enter upon operative technicalities. Quite apart from the fact that the time at my disposal is much too short to allow of such an ambitious scheme, it would frustrate, I am afraid, my very purpose. For I should have to go into such a mass of details that amongst them sight might be lost of the general principles which, in my opinion ought to govern our actions in this class of affections. It is with these I am mainly concerned. With regard to a few important and frequent diseases only, such as adenoid vegetations and laryngeal tuberculosis, shall I enter into details, because experience has shown that even with regard to such details some general principles of thought and action are required. For the rest, if the ideas which I am going to lay before you should be found worthy of your acceptance, it will not be difficult for you, I believe, to evolve from them a line of guidance in contingencies and affections which I may not happen to mention at all.

For my special purposes the symptoms and objective manifestations arising in pathological conditions of the upper air passages may be subdivided into the following categories :

1. Affections of a purely local character.

2. Local manifestations of general or systemic diseases.

3. Local manifestations in nose and throat dependent upon local diseases in correlated areas.

4. Affections of the upper air passages, supposed to exercise an influence upon other organs and parts of the body. This infuence may be: $(a)$ of a direct character; $(b)$ of a reflex character.

5. Local symptoms and sensations of obscure origin.

(A certain amount of overlapping is inevitable in adopting these subdivisions, but it will be minimised as much as possible.)

In conclusion, I shall have to make some observations on : 6 . The necessity of a proper proportion being observed between the gravity of the disease and that of the interference.

\section{Affections of the Upper Air Passages of a Purely Local} Character.

It goes without saying that as a rule the question whether local treatment should be adopted or not in a given case will be easiest to decide in the class of diseases now under consideration. Indeed, it may be stated as a general principle that if a disease of the upper air passages be $(a)$ purely local, (b) causing considerable local discomfort or serious disturbance of the general health, and (c) amenable to local treatmentsuch should be adopted forthwith without precious time being lost by a policy of mere waiting or by constitutional treatment, the effect of which in almost all such affections is at best extremely doubtful and in most nil.

You see, gentlemen, my proposition is, in all conscience, broad and radical enough to satisfy the most thorough-going localist. It embraces acute and chronic inflammations, abscesses, new growths, foreign bodies, hypertrophy of glands, all the various forms of obstruction, and, indeed, any other affections of the nose, naso-pharynx, pharynx, larynx or trachea, the purely local character of which can be ascertained and the nature of which demands active measures. But it limits the indication for active measures to cases in which they are really needed, by stipulating that they should only be adopted if the affection in question causes either considerable local discomfort or seriously disturbs the general health. And in this demand lies the crux of the whole question. No reasonable person will object to the removal of a nasal obstruction which almost entirely abolishes nasal breathing, and in addition causes dry pharyngitis and great liability to laryngeal and bronchial catarrh; to the radical operation of a chronic frontal sinus empyema, which produces violent frontal headache, gastric symptoms, grave disturbances of the general health and makes life altogether unbearable; to the removal of adenoids, which seriously interfere with the little patient's breathing and hearing and gravely jeopardise his chance of growing into a strong and healthy person ; or to the removal of a laryngeal papilloma or fibroma which renders the patient aphonic and threatens to choke him. I repeat: In all such, and in a large number of similar cases, it will be the practitioner's obvious duty to at once attack the local disease by energetic local measures, and I am so far from counselling a weak attitude in this class of cases, that on the contrary I wish to avail myself of this opportunity to strongly urge again, as I have done more than once before, greater energy in two classes of affections, in which one sees but too often the lamentable consequences of a policy of ignorance and procrastination. I refer to foreign bodies in the upper air passages, and, particularly, to malignant disease of the larynx.

With regard to foreign bodies it ought to be a fundamental principle: never to allow them to remain impacted, even though at first they may not produce serious symptoms! Disregard of that rule leads, frequently enough, to sericus consequences. In the nose small foreign bodies, which at first caused no discomfort whatever, have been often found to have served as nuclei for rhinoliths, which not only were the cause of chronic fœtid discharge, but the ultimate removal of which presented considerable difficulties. From the pharynx pointed foreign bodies, the immediate removal of which was neglected because they caused no urgent symptoms, have found their way into the tissues of the neck or into the thorax, and have caused fatal hæmorrhage by arrosion of large vessels. In the larynx foreign bodies, when left alone, may either cause perichondritis and lasting disablement of the larynx, or may become dislodged and fall into the lower air passages, where they may cause trouble of the most serious description. I have seen examples of almost all these contingencies, all caused by neglect in the first instance.

Equally great, as in the class of affections just named, is the necessity of early and energetic local interference in malignant disease of the larynx. It has been conclusively shown that in a good many of those cases in which thedisease begins in the interior of the larynx, more particularly on the vocal cords, it can be lastingly cured by so simple and comparatively non-dangerous an operation as thyrotomy with removal of the affected area and a zone of healthy tissue around it, provided only that the diagnosis be made sufficiently early for the affection to be still limited and circumscribed in character. Unfortunately, however, in spite of all that has been said and written, particularly in this country, as to the trivial character of the initial signs in these cases, which usually are objectively represented by the one symptom: obstinate hoarseness, and though it has been frequently pointed out, over and over again, that obstinate hoarseness in a middle-aged person peremptorily demanded a laryngoscopic examination, not a few cases still come under observation, in which the history of the commencement of the illness points to a favourable chance having once existed, but in which nolaryngoscopic examination was made in the earlier stages, and in which so much precious time was lost by useless internal medication, changes of air and similar measures, that when the patient is at last seen by an expert the latter finds that the chance has been either entirely lost, or that a much more formidable and maiming operation was now required than had been originally necessary, in addition to which the probability of recurrence was now infinitely greater than it had been at the beginning of the disease. Such cases are so sad, and the responsibility of those who disregard the small beginnings is so heavy, that I would again earnestly plead, as I have done more than once before, for earlier recognition and adoption of the necessary energetic local measures in suitable cases of malignant disease of the larynx.

It is really time that the profession should shake off the unfortunate fatalistic belief in the incurability of cancer which still holds the public and paralyses all healthy progress in combating that scourge! As matters stand at present, it is not too much to say that the public actually fight against a more hopeful view, and against the most convincing operative results. If, in a case that had been operated upon, recurrence should unfortunately takes place, one hears at once the chorus: "Of course, cancer always returns." If however, the patient, in spite of all croaking and dissuading from operation which forms the common characteristic of patients' "friends," remains well ever after, one hears equally frequently: "But was it really cancer?" or even what has, 
at any rate, the merit of settling the matter to the speaker's own satisfaction: "It cannot have been cancer." Such being the general attitude, it is, I hold, the duty of the profession to educate the public towards a better understanding; to teach them that not all forms of cancer are equally malignant; that there is an enormous difference regarding the chances of operation in cancers of different parts; and that, if cancers of certain parts be recognised sufficiently early whilst the mischief is still purely local, and if they then be at once thoroughly removed, the chances of a lasting cure are very good indeed.

But whilst thus warmly pleading the cause of local treatment in diseases of the upper air passages where it is really needed, I have no word of defence for the notion which, I am afraid, is very prevalent nowadays, that the discovery, often enough accidental, of the slightest deviation from the normal -or what the observer may be pleased to consider as a deviation from the normal-should be immediately pounced upon as a signal for local interference, and should be visited by some operation or other. Not every little crest or spur of the nasal septum requires the saw, the chisel, or the trephine, not every little puffiness of the mucous membrane over the turbinated bones the galvano-cautery, or the snare No immediate radieal operation is necessarily indicated when a drop of pus is seen in the middle meatus of the nose, nor has the turbinotome to come into play each time the posterior ends of the lower turbinated bones appear a little fuller and more rounded than they usually are. Not every little bunch of adenoid tissue by chance discovered in the vault of the pharynx must needs be removed, nor ought every tonsil to be cut which slightly projects beyond the palatal arches. Not every granulation or every visible vein at the posterior wall of the pharynx demand the application of the galvano-cautery, nor must the uvula inevitably be clipped because to the man who considers it his duty to "do something" it appears to be a little longer than he would like to see it. No long course of astringent applications is peremptorily indicated when the vocal cords appear slightly pinkish in the case of a professional voice user, and not every singer's nodule demands operative treatment.

I know well enough that such views are diametrically opposed to that teaching according to which every abnormality should be set right, lest it should ultimately cause mischief of some kind. But whilst fully admitting that prevention is better than cure, I do not hesitate to say that one may go too far, even in the laudable intention to prevent mischief ; that life is quite endurable, nay, even enjoyable, though one should be the possessor of a small spur in the nose, or of some granulations in the throat, and that I honestly believe that local tinkering of the kind just described is equally little in the interest of the patient and in the interest of the good name of our profession. Yet this is what I am afraid is going on at present on a large scale, and of which one not only hears on all sides, but actually sees but too many examples. Let me give you but one illustration which quite recently occurred in my own practice. A young lady, recently married, nervous, excitable, and anæmic, complained of choking sensations in her throat, and of a desire to "swallow empty." She consulted a specialist, who found nothing to account for these sensations, but discovered in the vault of the pharynx a little adenoid tissue which, to his thinking, was larger than it ought to be. On examining her ears, he thought the tympana were somewhat retracted. On the strength of the result of this examination he advised the lady to have the adenoids removed, " as otherwise she might become deaf in both ears in six months." Yet this lady had never been deaf in her life, there was no deafness in her family, and she had never suffered from any symptoms referable to the existence of adenoids. The patient was of course greatly frightened, and a consultation was arranged between the first medical adviser and myself. I did not see the least reason for any operation, as I found no more adenoid tissue than one sees in large numbers of perfectly healthy individuals, and as the lady's hearing power was absolutely normal. The first adviser himself admitted that on that day there was no inward drawing of the drum membranes. As I considered the sensations complained of to be of the nature of simple paræsthesia due to her anæmia, we agreed to send the patient, before any opera. tion was undertaken, abroad to take iron waters and baths. She returned perfectly well.-In the course of the consultation, when the decision had been arrived at that no operation should take place at once, I asked the first adviser in private whether he had expected that the removal of the adenoid tissue would cure the sensations which originally had brought the patient to him. He admitted that he had not thought it would. Here, then, gentlemen, you have a case in which the patient seeks relief for a certain definite complaint. Nothing is suggested to relieve this complaint, but an operation is proposed to avoid an extremely unlikely, not to say imaginary, contingency, and the patient's nerves receive a considerable shock.

I should at this juncture like to make two observations which, though interrupting, perhaps, for a moment my chain of argument, ought not, I think, to be left out of consideration in a lecture of this character. The first refers to a lesson to be learned in connection to the case just narrated. I have the distinct impression, from what I hear and see, that it becomes more and more the fashion to frighten-perhaps unintentionally-patients by informing them of all possible contingencies that might happen if the operative procedure upon which the adviser has set his heart were not undertaken. Now I think that such information should be given very sparingly, not wholesale, and that the adviser should carefully discriminate, where it is in the right place and where not. I am far from condemning the practice altogether. Often enough it is not only the right, but the duty of the practitioner, to warn the patient to beware of the future. Take for instance the case of a middle-aged man who comes to consult you for hoarseness. He makes very light of the complaint. You detect a suspicious-looking growth on one of his vocal cords, but it is quite impossible to make out at once definitely whether it is malignant or not. You tell the patient -without, of course, mentioning anything of your suspicionthat you must see him again in a few weeks. He demurs to this and seems altogether inclined to consider you a little fussy. Well, in such case, in which the question of the diagnosis being established in time is everything, I think it is your duty to hint as delicately as you can, and always avoiding, unless you are driven to it, the dreaded word "cancer," that more serious developments were not impossible, and that in his own interest the patient ought not to let slip his chances. Usually the handling of these cases is extremely difficult, and no general rule can be laid down for them. The quality, which one patient will praise as frankness, and for which he will thank you, will be condemned by the othermore probably perhaps by his friends-as brutality, and, particularly if, after all, your fears should turn to have been unjustified you will for ever be decried by that patient's family and friends as an "alarmist." Still, in such a case, when you see that a patient may lose his only chance from ignorance of possible developments, I hold it is your plain duty not to let him do so. - Or, to give you another example of more frequent occurrence: Suppose a mother brought you a child suffering from well-marked adenoid vegetations with $\mathbf{a}$ history of more or less permanent deafness, aggravated periodically during colds and accompanied at such times by violent earache and purulent discharge from the ears. Suppose, further, as so often actually happens, that she began the consultation by expressing a strong hope that you would not recommend an operation. Well, in such a case, it will be simply your duty, I think, when explaining the reasons why contrary to her wish, an operation should be performed, to emphasise the great danger of lasting and serious impairment of the child's hearing if matters be left alone. But such a warning, I hold, is an altogether different thing from frightening, as in the case just narrated, a patient who comes to you for some quite different complaint, who has never suffered from symptoms traceable to adenoids, particularly not from deafness, and who has long passed the age at which adenoids according to universal experience may exercise unfavourable influenees, iby the threat of deafness, if by accident you discover an insignificant amount of adenoid tissue in the vault of the pharynx.--Similarly, the threat of deafness seems to me inadmissible, if a patient who never in his life has complained of his nose is found to breathe a little less well through one nostril than through the other, owing to some trifling irregularity in the configuration of his 
nose, and, again, I think it is very undesirable to frighten a patient with the threat of brain complications in an ordinary case of ethmoidal suppuration.

In close connection with the point just discussed is the second one to which I wish to draw your attention. Let me advise you not to hurry patients into operations you may have to recommend, unless there be most cogent reasons for hurry. That cases occasionally occur which do not brook a moment's delay I am far from denying. I have a few times had patients in my consulting room with such dyspnœe, that it was touch and go whether tracheotomy might not have to be performed there and then. On more than one occasion have $I$ at a first interview opened retropharyngeal or peritonsillar abscesses, removed foreign bodies from the upper air passages or from the œsophagus, plugged the nostrils in cases of uncontrollable epistaxis, scarified the laryngeal mucous membrane for acute odema threatening asphyxia, and performed similar urgent operations. In such cases delay, I need not say, would mean dereliction of duty, and further, if the topical application should be of so trivial a character as not to deserve the name of an operation, I see no objection to its being made at once, if at all required, in order to spare the patient a needless repetition of his visit. Thus everybody, I dare say, will apply if necessary the electric current, or the galvanocautery, or an astringent on the occasion of a first consultation. But these cases are altogether different from those in which overzealous operators not merely magnify insignificant affections into most serious diseases and discover reasons for immediate operation which are unfathomable to other observers, but give the frightened patient no time for consideration, and either perform the operation there and then or in one of their surgical homes within a few hours from the first consultation. Several well-authenticated instances of that deplorable practice have come under my own notice.

I have left until the end of this division of my subject the discussion of local treatment in an affection which only a few years ago appeared to have been so completely threshed out from all possible points of view that nothing more could be said of it, but which quite recently has been undergoing so curious a development that it becomes an urgent necessity to again enter more fully upon it. I speak of adenoi'd vegetations in the vault of the pharynx. The history of that affection in Fngland has been very remarkable, and well illustrates the vicissitudes of medical fashion referred to in the introduction to this lecture.

Although Wilhelm Meyer's paper on the subject was read before the Royal Medical and Chirurgical Society as far back as 1870, it is no exaggeration to say that the subject up to about 1880 was practically unknown to the profession at large in this country. I well remember that in 188I I proposed removal of adenoids in the case of the daughter of a personal friend of mine, and that the father was so startled by the suggestion of so unheard-of an operation, that before consenting he wished for a consultation with one of the leading physicians of that time. I of course agreed, and the consultation was opened by my consultant asking me, "I say, Semon, what are these things?" That was in 1881!-For several zears after that date the operation practically remained in the hands of a few specialists, and it was during that time that one frequently heard unkind remarks about the specialists having invented a new disease. The benefits, however, accruing from the performance of the operation in really suitable cases, were too obvious to be overlooked or killed by ridicule. The operation slowly came to be practised in the general hospitals, its originally rather crude technique was much improved by the invention of Gottstein's curette, and by the introduction of anæsthetics into its performance. The original detractors became not merely silent, but not a few were changed into enthusiastic converts, and about 1890 the shortly before despised operation became the rage of the day. Everybody performed it, everybody gave the anæsthetic, the originally limited indications were rapidly extended, particularly when "reflex neuroses"-of which more anon-became fashionable, and ultimately it seemed as if every child required an operation for adenoids. "Have your children already been 'done'?" was-and in some places even now is - the elegant question put by one anxious mother to another at fashionable afternoon teas. When a child caught a little ebld, and snored for a night or two, the mother or governess themselves diagnosed adenoids, or, as they preferentially call them, "aneroids." When a boy brought home a bad report from school, the cause must have been edenoids; when a child suffered from asthma stammering, enuresis, epilepsy, laryngeal papillomata, and what not-adenoids again! In fact, "when in doubt, say adenoids," appeared to become a maxim of contemporaneous pediatrics!

But the hardly-won popularity was not to remain long uncontested. It was about 1891 or 1892 that I first had the question-which nowadays forms one of the stock ingredients of all these consultations-put to me by an anxious mother, whom I advised to have her child's adenoids removed : "But don't they always grow again ?" I well remember how surprised I was at that notion, which at that time I considered extremely curious. Gradually, however, the everincreasing frequency of the question, and the fact that more and more often children were brought to one whose post-nasal spaces, although they had been only recently operated upon, were as obstructed by adenoids as if nothing had ever been done, taught one, that recurrences now occurred with a frequency never heard of in the old days, and that the parents' questions concerning them were much more justified than had seemed at first. Soon afterwards sinister rumours spread as to fatal results which had in various instances attended the operation. They at first received little credence, but when in 1896 statistics were published showing that between the commencement of 1892 and April, 1895 , that is, in two years and a quarter, no fewer than I deaths had been actually reported in England alone as having occurred in operations performed under chloroform for adenoids and tonsils, general alarm was felt. Chloroform as an anæsthetic in these cases was considered unsafe by many. Anæsthetics having a shorter lasting effect, such as ether and nitrous oxide, were resorted to, and it became an ambition to perform the operation in the minimum of time. It was boasted that it could be done in forty-five seconds, and as late as 1899 a professional anæsthetist referred in a discussion on the choice of an anæsthetic to operations for adenoids, which occupied "a few seconds, or perhaps half a minute" in their performance. Thus everything gradually combined to damage the prestige of the operation-wholesale performances in cases in which, to say the least, it was not needed; faulty, or at least extremely hypothetical, indications; in but too many instances, technically insufficient execution; a dread of chloroform as an anæsthetic during its performance; and a widespread reputation of recurrences. The natural result of all this was bitter disappointment on the part of many parents who had reluctantly given their consent to the operation on the strength of glowing promises concerning improvement in the general health, and disappearance of all possible troublesome symptoms in remote parts of the child's body which would certainly follow its performance, and who saw none of these promises realised. A paper recently published by a lady in one of the monthly reviews depicts graphically enough what is felt in large lay circles about the whole question.

But already previous to its appearance the unavoidable reaction had occurred in the profession itself. Mr. Arbuthnot Lane took up the cudgels against the massacre of the innocents in two papers published in 1897 and in 1899 . In the first he declared that operative procedures were, in his opinion and experience, "quite unnecessary," and that "systematic ventilation of the lungs and naso-pharynx provided us with a means not only of applying to the naso-pharynx such force as is exerted by air being forcibly drawn through it, but by oxygenating the blood more fully and removing more thoroughly the carbonic acid, etc." All these desirable results were to be obtained by systematic " breathing exercises" in poorer cases a printed slip being given to parents containing the following simple instructions: "Put the child on its back three times a day for half an hour at the time, and make it breathe in and out as deepiy as possible through the nose, the mouth being kept shut." The second paper brought important modifications of these sweeping statements. Whilst in 1897 the author had declared that operative procedures were "quite unnecessary," and that "unfortunately for the patients, surgeons under the influences of the suggestion of Wilhelm Meyer had considered that the secondary infec- 
tion of the so-called pharyngeal tonsil was the primary cause of the obstruction of the naso-pharynx, and had hoped to cure the patients by cutting away a varying portion of the substance," he was good enough to admit in 1899 that after all there was a "very small proportion" of cases in which the operation was required in order to "establish a through way" or to " telescope the duration of treatment." He says in conclusion: "The only circumstances under which I can understand the surgeon being warranted in attacking the pharyngeal tonsil are: (1) When the condition has been so thoroughly neglected that the child is unable to drive air through the naso-pharynx, when development has been long in abeyance until the enlarged pharyngeal tonsil has been effectually removed; (2) when for some reason or another, such as considerable difficulty in forcing air through the nose, ear trouble, important school or other arrangements, peculiar circumstances, etc., it is necessary or desirable to telescope the duration of treatment; and (3) when the child is too young to do what it is told."

I think it is a very great pity indeed that Mr. Arbuthnot Lane should not have stated in his first paper the indications admitted in his second, which "warrant the surgeon " in telescoping the duration of the treatment. Had he done so, it would have been seen, I feel sure, that apart from his absolutely unproven theoretical ideas as to the origin of adenoids, the difference which separated him from the moderate section of his surgical confrères was not one of kind, but only of degree. For this moderate section also advises operation in such cases only as he admits as legitimate in the concluding sentences of his second paper, and so far as matters of fact as concerned, the only real point of contention between him and them is this, that the cases in which operation should be performed, in his experience, constitute "a very amall proportion only" of the whole number, whilst they find that the very circumstances enumerated by him-long-standing neglect, very considerable obstruction, deficient. development; ear troubles, important school or other arrangements, "peculiar circumstances," young age of the patients-are met with considerably more frequently than in "a very small proportion only.

Meanwhile, however, the wholesale condemnation of the operation in his first paper, and particularly the suggestion of the "breathing exercises" had caught on. Society, ever on the outloek for some novel sensation, is as fond of changing its medical fashions as any other. Yesterday it was the bonesetter, the marvellous voice-producer, a new method of dieting, hygienie underclothing of some particular kind, antipyrin, massage, thyroid tabloids, antifat, et hoc genus omne, that : were the rage of the town; to-day it is some new medical genius -4 a perfect wonder, my dear"-just discovered by a leader of society or a prima donna; the Kneipp cure, or its degenerate progeny, the sandal craze ; Christian Science, rheumatism rings, a new brand of 'Moselle, electric light baths; that are in everybody's mouths. What it will be to-morrow nobody knows; it is characteristic of Oocietyis rages that they almost always have a very ephemeral existence. Thus with the adenoid mania: The question, "Have your ehriddren already been done?" was really becoming a little stale; fresh fields and pastures new were wanted; the difficulty was only to find something original that would suitably replace the old fashion. At last the revelation came w-breathing exercises! "I thank thee for that word" must have -been the thought of many a professor, of calisthenics, massegeyrgymastics, and corpulence curer with a keen eye to Hburiness; $^{2}$ who perceived that here a new and promising opening offered itself. No sooner said than done: departments for: " breathing exercises:" were opened, the public flocked to them in their thousands, a roaring trade was and is being done at this moment, and children galore, who otherwise would have ibeen operated upon by the doctors, are'now; if reports be true, cured or enormously improved by so simple a means as breathing exercises.

But are they?

Well, gentlemen, I may be an incurable sceptic, bat I have no hesitation in telling you that I do not believe for a moment that a single child which has got well-marked adenoids has been, or ever will be, cured by breathing exercises, all reports to the contrary notwithstanding? I mean no disespect to Mr. Asbuthnot Lane; but I camot help saying that the whole idea seems to me preposterous. Whether adenoids be secondary to "infection of the nasal mucosa" or not, there can, at any rate, be no doubt that they obstruct in well-marked cases the airway, and thereby most efficiently prevent that ventilation of the lungs which, according to Mr. Lane himself-and, may I add, according to every reasonable observer before him who has worked at the subject - is of such enormous importance. It logically follows that the obstruction, whether primary or secondary, must be got rid of as a first step towards enabling the patient to breathe freely and to ventilate his lungs. This surgeons have hitherto done-and no doubt will continue to do-by "telescoping the treatment," or, in other words, removing the obstruction in the quickest and most complete way-that is, by operation-just as they would do under analogous circumstances in any other part of the body. But, according to Mr. Lane, this is, with a very few exceptions, "unnecessary, imperfect and unscientific," since it deals only with an effect, and not with the primary source of infection. In view of the many thousands of cases, which beyond the shadow of a doubt have been cured by the unnecessary, imperfect, and unscientific treatment-and, mark you, by this treatment alone-which $\mathrm{Mr}$. Lane condemns, it certainly demands some courage to make such a statement. His adversaries, however "unscientific" they may be, certainly have facts on their side. And if it should be called "unscientifie" to say plainly that the rationale of his treatment was a mystery to them, I for one must plead guilty to that soft impeachment. How a genuine lymphoid hypertrophy can ever be expected to be dispersed by "breathing exercises" completely passes my understanding. Is it by the air being forcibly drawn over it? If that were possible, will Mr. Lane explain how it is that in so many cases of much-developed adenoids there are at the same time much-enlarged tonsils?. It would seem to me that if forcible breathing could disperse lymphoid tissue : in those cases in which nasal breathing is reduced to a minimum, and in which the patients have thus been compelled to forcibly breathe, not for half an hour three times a day, but all days and all nights for many months or even years, the effect of the forcible passage of air ought certainly to show itself in the disappearance of the enlarged faucial tonsils, which in structure are so very similar to adenoids. But, unfortunately for Mr. Lane's theory, these do not disappear; on the contrary, they flourish!-On what grounds, then, are "breathing . exercises" expected to act beneficialiy in cases of genuine hypertrophy Are they to do wonders by imparting " force" to the nasopharynx; or is it thought that'half an hour's "oxygenation" of the blood three times a day in twenty-four hours will in such a miraculous way alter the constitution as to make the actual obstruction of the air passages disappear? I fail to discover other arguments in Mr. Lane's papers, and I hope he will not be too indignant with me if I frankly state that his "breathing exercises" appear to me simply in the light of a scientific glorifieation of the obsolete advice referred to in the introduction of this lecture, and so freely administered to the unfortunate sufferers before Wilhelm Meyer's beneficent discovery," Keep your mouth shut, Shut your mouth."

Not that I despise breathing exercises in their proper place. On the contrary, for many years: before Mr. Lane ever gave public utterance to his ideas I'like, I dare say, most operators, have been in the habit of telling mothers that after the removal of the obstruction, they must insist on the child's learning to breathe through the natural air channel-namely, through the nose, and that if admonition alone failed to cure the habit of mouth breathing, engendered by : months' or years' impossibility of preathing through the nose, they must use for some time some simple contrivance which covered the ohild's mouth, completely, and compelled it to breathe through the nose. An apparatus of that sort was recommended many, many years ago by Professor Guye, of Amsterdam, under the name of "contra-respirator." It is nothing else but an anticipation of Mr. Lane's leading idea, the only difference being, in my humble opinion, that it brings in "breathing exercises" in their proper place, whilst Mr. Lane, if he will excuse me for saying so, seems to me to put the cart before the horse.

Now, I shall probably be told that all my theoretical 
objections go for very little in view of the fact that the patients were cured by the breathing exercises. But, I repeat, is it a fact? I do not believe it. Not that I doubt the good faith of those who think that they have seen cures, but I feel convinced that in such cases transitory congestion of the lymphoid tissue in the vault of the pharynx has been mistaken for actual hypertrophy. In such cases I can easily enough imagine what has happened. The lymphoid tissue, being very vascular, easily becomes the seat of catarrhal inflammation, when it swells considerably, and pro tem. may present all the symptoms of genuine adenoids. Now suppose that a child was taken during such an attack to a medical man because the mother wished him to see the patient "at his worst," a casual examination might easily enough result in the verdict "adenoids" and in the advice "operation." The mother, dreading operation, decides that a trial should first be given to the "breathing exercises" of which she has heard so much of late. The child is put through a course which lasts several weeks, if not months, and all the symptoms disappear. That exactly the same result would have been obtained if the child had simply been taken a little care of, but otherwise been left alone, does not, of course, enter for one moment into the consideration of the happy mother (and how could it?). Lavish praise is heaped upon the breathing exercises to which alone the credit of the recovery is given ; and the doctor is severely blamed for having recommended a perfectly unnecessary operation. Considering the frequency of these inflammatory attacks, and the readiness with which nowadays the advice to remove adenoids is given, the number of such cases, in all probability, is very considerable, and it is easily enough intelligible that they should have lent colour to a perfectly honest belief in the efficiency of breathing exercises. But beliefs are not facts, and how little the actual facts agree with Mr. Lane's teaching the following case, which recently occurred in my own practice, will show you.

A little girl had suffered for a long time from well-marked obstruction of the naso-pharynx, mouth-breathing, thick voice, snoring at night, commencing pigeon breast, tendency to colds, earache, anæmia, and weak state of general health. At the suggestion of the family doctor she was taken to a distinguished surgeon, who diagnosed, as the family doctor had already done, adenoids, and recommended their removal. The parents being much averse to operation, took the opinion of another authority, who advised breathing exercises. The child was placed under a professor of Swedish gymnastics, who makes, I am told, a speciality of such exercises, and for two months assiduously went through a course. Meanwhile, the parents flattered themselves that they observed considerable improvement in the child's symptoms, whilst the family doctor was unable to perceive it. Whilst still under the treatment the child caught pneumonia and nearly died. During the acute disease her respiratory difficulty was so obviously increased by the impossibility of breathing through the nose that the family adviser insisted that after her convalescence yet another opinion should be taken. I was consulted, and found the nasopharynx crammed full of adenoids. Remember, this child had been treated for two months with breathing exercises! I, of course, warmly supported the family doctor's and the first consultant's advice ; the parents at last consented. The child was operated upon by the surgeon first consulted, whe found, he told me afterwards, the naso-pharyngeal cavity, as I had found it, crammed full of genuine adenoids, and who added that he had quite recently received a letter from the father, warmly thanking him for the genuine improvement which since the operation had taken place in the child's local symptoms and general health.

It did not require the lesson taught by this case to convince me of the untenability of Mr. Lane's teaching, but it is valuable as showing that practical experience no less strongly than theoretical consideration militates against what I am afraid I must call an exaggeration in the ultra-conservative direction.

But whilst thus defending Wilhelm Meyer's beneficent discovery against the onslaught of a solitary adversary, I am at least equally anxious to save it from the much more dangerous indiscretion of its injudicious friends. There is not the least doubt in my mind from what comes under my personal observation, that a great amount of over-operation of slipshod nature is going on with regard to adenoids, and if we wish to prevent a good operation from falling into bad repute, it seems to me necessary to come to a much more precise understanding, as to the conditions under which operative interference should be recommended and how it should be carried out, than exists at present.

I would deduce the following principles as helpful

With regard to the question of operation, adenoids may fitly be subdivided into three classes, according to whether they cause: (a) permanent, (b) periodical and transitory, (c) no symptoms.

The first class, the "typical adenoids," embraces the cases in which respiratory obstruction, open mouth, snoring, thick voice, deafness, are all, or some of them, always present, and in which the altered type of respiration may have already led to the peculiar deformities. of the face and chest, and to a general debilitated state of health. In this class-in my experience a very large one-I consider operation absolutely indicated, and I advise it the more strongly the further away the child is from the period of puberty, at which often enough, though by no means always, spontaneous atrophy of the growths occurs. For even if the condition should never become complicated, as it so often is in these cases, by inflammatory ear affections, or by one or another of the febrile diseases of childhood, the mere alteration of the natural type of breathing and the deficient aerration of the lunge will, if unrelieved for years, leave their ineffaceable traces in the physiognomy, physique, and entire mental and bodily development of the patients. Seeing that all these serious consequences of the obstruction of the air-way and hearing channels can be prevented by so simple and comparatively safe an operation as the removal of adenoid vegetations, I hold it to be the practitioner's bounden duty strongly to urge operation in this category of cases. It is the one which has established the well-deserved fair fame of the operation, the result of which under such circumstances is always very gratifying, and often truly astounding.-In exceptional cases this applies also to the removal of adenoids in adults, but such cases are, in my experience, extremely rare.

Much more difficult is the question of operation in the second class, in which free intervals alternate with periods of nasal obstruction and impairment of hearing, or attacks of earache, and even of otitis media. This is the category previously referred to, in which during the free intervals only a very moderate, or hardly any, organised hypertrophy of the lymphoid tissue may be present, but in which on the slightest catarrhal provocation so much congestion and engorgement occurs, that for the time all the symptoms of the first class-the genuine adenoids-are closely simulated. It may well be that opinions with regard to the advisability of operation in one and the same case belonging to this class should diametrically differ according to the period at which the little patient is seen. A. sees him "at his worst," a mouth-breather, snuffling, with thick voice, very deaf, and with some otorrhœea, and strongly advises operation. B. sees him a few weeks later, when the acute attack has passed off and all these symptoms have temporarily disappeared, and cannot understand why A. should have recommended operation.

I may observe here that $\dot{I}$ am afraid that, owing to our great familiarity with the affection, some of us pay insufficient attention to the-often enough rather emphatic-statements of the parents, governesses, or nurses as to the periodicity of the symptoms. This, however, is a very important point. It is just this class of cases in which the most experienced may make mistakes. Suppose he urges strongly that the operation should be performed as a prophylactic measure, suppose that the advice is not followed, and that nothing serious occurs, he is certain to be put down by the parents as an alarmist and fanatical operator. Should the child meanwhile have gone through a course of "breathing exercises," it is they which get the kudos of the improvement. Suppose, on the other hand, that, guided by the desire to spare the child a possibly unnecessary operation, one votes against operation or, at any rate, in favour of postponement, and that unfortunately shortly afterwards acute ear complications should arise or an abscess form in one of the lymphatic glands 
or pulmonary troubles occur, to which these patients seem rather prone-one is equally severely blamed for not having spoken more strongly in favour of an operation which might have obviated all these deplorable and sometimes lasting consequences. What I would recommend under these circumstances, although no formula will fit all cases, and occasional errors of judgment are almost unavoidable, is this : If a child be brought to you " at his worst," but with a definite statement that these attacks occurred only very rarely, that they lasted but a short time, and that in the intervals the child enjoyed perfect health; if you find some soft swelling of the lymphoid tissue in the vault of the larynx, but no evidence of organic ear disease; and if altogether you gain the impression that the child had been brought much more because the mother was anxious than because there were any really urgent symptoms, express a desire to see the child again under, what would be for it, normal circumstances, and postpone the decision with regard to operation until then. If the symptoms be more grave, particularly if there should be marked deafness, perforation of the tympana, otorrhœa, enlargement of the lymphatic glands in the neck, a tuberculous family history, vote in favour of operation as a preventive of more serious events, which, in view of the circumstances named, might reasonably be expected. If you are in doubt yourself-as in these " half-way house" cases the most experienced observer often enough is-let me recommend you to lay as clear and non-alarming a statement as possible of the actual conditions and of the various possibilities of development before the parents, and let them decide themselves. This course will equally protect you against being called an "alarmist" and "very fond of operations" on the one hand, and against being accused of having "neglected" the case on the other.

Concerning the third class, I have only to repeat what I have said in the earlier part of this lecture, nameiy, that adenoids which do not cause any symptoms do not, in my opinion, require removal. One often enough in the course of a methodical examination of the upper air passages discovers a not inconsiderable amount of lymphoid tissue in the vault of the pharynx, which evidently has never done any harm, just as one often enough sees somewhat enlarged faucial tonsils which have never given rise to the least inconvenience. Such innocent hypertrophies should, I feel sure, be left alone, particularly in adults, and all the examiner might tell the patient, in order to safeguard himself against an imputation, that he had "overlooked" the condition, is, that there was a slight fulness, but that this, unless it should cause any symptoms, did not require operation.

These are the suggestions which I have to make with regard to the indications for operation. You will probably be surprised that amongst them I have not mentioned, by one single word, the so-called "reflex neuroses" for which they are so frequently undertaken. Well, gentlemen, in my second lecture you will hear that I am a great sceptic with regard to "reflex neuroses" arising from the upper air passages in general, and I will say at once that I am particularly so with regard to reflex neuroses said to be due to adenoids. I am not in the habit of doubting the reports of others, simply because I have had no analogous experiences, and I have already told you, as was my duty, that obscure affections of the most different kinds have been attributed to adenoids, and are stated to have been cured by their removal. Personally, however, I must say that I have never performed any operation for adenoids for the express purpose of curing one of these reflex neuroses, though I need hardly tell you that in the course of the last twenty years plenty of these cases have come under my notice. In such of these cases in which I found an insignificant amount of adenoid tissue and none of the classical symptoms accompanying it, I have not been able to bring myself to the belief that asthma, epilepsy, enuresis, and similar neuroses, which had been ascribed to the adenoids, were really due to them, and I have therefore not seen my way to advise operation. But in cases in which besides the reflex neuroses ascribed to them the adenoids caused actual tangible respiratory and auditory symptoms-and I have seen a good many of such cases too-I have operated, always thoroughly explaining to the parents beforehand, in order to avoid disappointment, that $I$ advised operation only for the sake of removing the obstruction which interfered with breathing, hearing, and general development, and that I could give no promise whatever as to the cure of the reflex neurosis. That caution in my practice has turned out to have been a very judicious one, for in not one single case have 1 ever seen a so-called reflex neurosis disappear after removal of adenoids in such a manner that I could rightly have spoken of a causal relation between the two. True, in a few cases I heard long afterwards that asthma, enuresis, epilepsy, etc., from which little patients of mine had suffered at the time of the operation had disappeared, or at any rate diminished; but then it is well known that these neuroses often enough improve spontaneously, and in all my cases the interval between the operation and the commencement of the improvement had been much too long to justify me in attributing the improvement to the operation itself, or to its influence upon the general health. On the other hand, I know positively of not a few of my own cases in which, though the general health had been materially improved and the direct symptoms due to the adenoids completely disappeared, the reflex neuroses persisted for many years afterwards with undiminished intensity. Only quite recently I saw a boy of 9 , who six years ago was sent to me for most troublesome salivation, said to be due to adenoids. Adenoids there were, certainly, and in such quanties as to seriously interfere with the child's breathing and general development; but why they should cause the salivation was more than I could understand without taking refuge in most artificial theories. I advised and performed the operation for the general reasons just named, but I strongly warned the mother that I could not in the least promise disappearance of the salivation. When I saw my little patient a few weeks ago he had developed into a very fine strong boy, but the ptyalism was just as unpleasantly there as it had been six years ago. Similar things I have seen in connection with asthma, stuttering, stammering, enuresis, epilepsy. Experiences of this kind fully warrant me, I think, in strongly advising you not to be too sanguine with regard to the connection of adenoids and reflex neuroses. To promise positively a cure of the latter if only the adenoids be removed, as I know has been but too often done, I consider simply unwarrantable.

Finally, in this connection let me warn you, as others have already done before me, against too hastily diagnosing adenoids from facial appearance and nasal obstruction alone. Although the "adenoid face" in a fully-developed case is characteristic enough, deformities of the nose itself and of the hard palate, as well as enlargement of the posterior ends of the lower turbinated bones, may closely simulate the symptoms produced by adenoids, and it ought to be an invariable rule, therefore, to decide for operation on the strength of thorough examination only-a rule which, I am afraid, is not always adhered to. As to the examination itself in a good many cases, particularly in elder children and in adults, posterior rhinoscopy will suffice, without the unpleasant investigation by the finger being resorted to. In all cases, however, in which there is the least doubt I strongly advise you to employ digital exploration, which in these cases, I do. not hesitate to say, is greatly superior to mere inspection, inasmuch as it gives you much more reliable information about the quantity of growths present than is afforded by the rhinoscopic mirror.

So far as the operation itself is concerned, I would impress you with one principle:-Operate thoroughly !-I have not the least wish to lay down dogmatic rules as to the technique of the operation, although I hold very strong opinions on that point as well. But, whatever method you may employ, operate thoroughly, gentlemen, and never forget that the question is not whether the child is forty-two seconds and ahalf or five minutes under the anæsthetic, provided that the latter be administered, as in these cases it always ought to be by a competent anæsthetist, but whether there is to be a recurrence or not.

Next to over-operation, I have no hesitation in saying that nothing has so much damaged the reputation of the operation than the frequency of so-called "recurrences" observed of late years. No doubt, perfectly genuine recurrences will occasionally take place, even after very thorough operations but such an event is, in my own experience as well as in that of all thorough operators with whom I have discussed that 
question, very rare indeed, and I have not the least doubt that what is commonly called a "recurrence" is in the enormous majority of cases in reality " incomplete operation." One must have seen such cases shortly after operation in order to be enabled to judge in what an incredibly slipshod manner the operation is nowadays but too often done and how the cry "recurrence" has come to be raised. A whiff of gas, a little scraping with the finger-nail, and behold! the "operation" has. been performed, and the parents are left in the belief that all has been done that could be done. A few months, nay, even weeks, after the "operation" the old symptoms come on again; the parents in distress seek another opinion, and, when they are told that the operation has to be performed anew, ask in despair: "But don't they always grow again?

Against this class of "recurrences" there is only one safeguard, but it is a very efficient one: thoroughness of operation, and this thoroughness must be preached until it is generally practised. I need hardly say that this thoroughness is not equivalent to violence. Unfortunately, whilst one very frequently meets with instances of under-operation, one occasionally comes across sad examples of the other extreme. I have seen cases in which the operator had so proceeded that the ugliest adhesions had formed in the naso-pharyngeal cavity and between the soft palate, the pillars of the fauces and the posterior wall of the pharynx. An aspect, in fact, resembling that of cicatrisation in congenital or tertiary syphilis, and in these cases the articulation of the victims was materially and lastingly impaired. That certainly is not the kind of thoroughness I recommend. But the desirable thoroughnees I have in view can only be obtained, so far as I can see, by the operator being in the position of not being hurried unduly by the brief duration of the anæsthesia, nor by the fear of any untoward event during the operation itself.

Personally I have not the least doubt that these conditions are most ideally obtained by $(a)$ chloroform being selected as an anæsthetic in these cases; and by $(b)$ the patient being operated upon in the recumbent position with his head well bent over the back of the operation table. If chloroform be quietly and slowly administered by a competent anæsthetist, and never pushed to the abolition of the cough reflex, it introduces, to the best of my conviction and experience, no amount of danger into the operation, and it gives the operator time to remove the growths thoroughly: If the recumbent position be adopted, with the head well over the table, there is no danger of blood or a loose fragment of adenoids penetrating into the larynx or lower air passages. These-as I consider them-most essential conditions having been secured, the operator can then at his ease thoroughly remove the growths. by whatever instruments he prefers (personally I almost always use the two models of Gottstein's curette, the curved and the straight one, and Hartmann's laterally-cutting curette, whilst in exceptional cases only I employ Woakes's modification of Loewenberg's forceps). The operation ought not to be considered as finished until the nperator, by thorough digital exploration, has convinced himself that not a vestige of lymphoid tissue projecting over the surface of the mucous membrane has been left behind. Should the tonsils have to be removed at the same time, I usually remove the adenoids first and the tonsils afterwards. Only when the tonsils are so large that it is impossible to introduce instruments into the naso-pharyngeal cavity, without impeding respiration, I remove them first. I have heard my method described as "fussy," but it is safe, and it certainly yields infinitely fewer recurrences than that of the lightning operator. No after-treatment of any kind is necessary beyond keeping the patient in bed for twenty-four hours, and in the house for two to three more days, an aperient being given the first evening, if there should be a rise of temperature. I warn especially against any "antiseptic" injections being made through the nose. It is many years since I gave them up completely, and I am glad to be able to state that I never since have had an acute ear complication.

Others may prefer other methods. I have not the least wish to assert that the method I recommend is the best, or the only one by which success may be secured, but from long and ample experience I can honestly state that it answers all reasonable requirements, and if you proceed by it, selecting suitable cases only for operation, you may be confident that you will maintain the prestige of one of the most salutary operations of modern times.

If, in conclusion of this lecture, I were to briefly summarise the advices given in it, I should say this: In all purely local affections of the upper air passages there are certain cases in which all reasonable men will agree that local treatment is required, and others in which the moderate section at any rate will be unanimous that it is not. Between these two classes there is the very large intermediate one in which everything is a question of "degree," and in which opinions may legitimately differ as to whether local treatment should be adopted or not. Far be it from me to assert that occasionally mischief may not be done by doing too little, but if I endeavour to judge impartially the current of opinion at the present moment, I have no hesitation in stating that if at all, we err at the present moment in the opposite direction, and I cannot better sum up the advice which I think should at this juncture be given, than by reminding you of Talleyrand's celebrated counsel to a young diplomatist who for the first time was sent on an independent and responsible mission: "Above all, not too much zeal !"

\section{A REMARKABLE CASE OF AORTIC ANEURYSM OF SIXTEEN YEARS DURATION : DEATH FROM RUPTURE EXTERNALLY.}

BY T. R. C. WHIPHAM, M.B., B.Ch.OXoN., M.R.C.P.LOND. Medical Registrar to St. George's Hospital.

The patient, a builder's foreman, was born in 1844 , and came of a rheumatic stock. He himself had had occasional joint pains, and had suffered at times from "fever and ague," contracted in Mexico in 1866. No history pointing to syphilis could be elicited. In 1884 he began to suffer from an incessant cough and indefinite thoracic pains, accompanied by loss of flesh, but it was not until a week before his first admission to St. George's under Dr. T. T. Whipham in April, 1886, that he noticed a swelling on the right side of the sternum ; for two months previously, however, anginal pains had been very severe.

When first seen there was a "rounded, regular, smooth tumour," $3 \frac{1}{2}$ inches in diameter, occupying the first and second right interspaces and the adjacent edge of the sternum. It was expansile, but no bruit was heard over it, though one was present in the right subclavian and carotid arteries. The aortic second sound was accentuated. The voice was hoarse and the cough suggestive of pressure, and there was also inspiratory stridor. Air entered the right lung much more freely than the leit, but there was no dysphagia. The right pulse was slightly the weaker of the two, and the pupils were equal. Pressure on the carotid and subclavian vessels on the right side greatly diminished the pulsation in the tumour, and distal ligature was proposed, but the patient declined operative treatment. During his first three weeks in the hospital the aneurysm increased rapidly in size till it eroded the whole of the upper part of the sternum, measuring $6 \frac{1}{4}$ by $4 \frac{1}{2}$ inches. Two eminences made their appearance on the surface, and the skin over it was tense, shiny, and discoloured. The patient at this time was described as being "weak, ill, and hopeless." Treatment consisted of a scruple to half-drachm doses of potassium iodide, with morphine, for the relief of pain, and the fluid part of the diet was restricted to a pint in the twenty-four hours. No further extension took place; on the other hand, the tumour began to steadily decrease in size and seemed to consolidate, while the prominences disappeared. The patient was kept in bed for eight months, at the end of which time the pulsating area measured only $\mathrm{I}_{2}$ by $\mathrm{I}$ inch. There was no paralysis of the vocal cords, and no bruit had at any time been audible over the aneurysm. The patient's condition had much improved, and he experienced no illeffects from getting up. He was discharged in January, 1887.

A year later he returned to work, and followed his employ 